\title{
O COLECIONADOR E O MUSEU, OU COMO MUDAR A HISTÓRIA DAARTE?
}

\author{
Chantal Georgel ** \\ Instituto Nacional de História da Arte - França \\ Ana Cavalcanti (tradução) \\ Universidade Federal do Rio de Janeiro
}

O colecionador e o museu, ou como mudar a história da arte? A questão se apresenta de modo abrupto, é verdade, e já prevejo uma série de objeções legítimas que podem ser feitas. Pois o colecionador só muito raramente é historiador da arte, isso quando não recusa inteiramente qualquer história da arte; e frequentemente está muito distante, no momento em que forma sua coleção e mais tarde quando a transmite ao museu, da intenção de escrever "uma página da história", como se diz, mesmo se, tal qual Monsieur Jourdain' que faz uso da gramática sem o saber, ele também faça história da arte sem querer. Sobretudo por que, e é nesse ponto que os murmúrios se fazem mais insistentes e até zombeteiros, devemos nos perguntar que relação o museu deve ter, se é que deve ter alguma relação, dirão alguns, com a história da arte. $O$ colecionador, o museu e a história da arte, aí está um ménage à trois, três parceiros aparentemente unidos em torno de um objeto chamado "arte", objeto material e intelectual.Três parceiros indispensáveis uns aos outros sem dúvida, mas portadores de objetivos, missões, ideias e intenções diferentes, e até mesmo contraditórias, e cujas ligações não cessaram e não cessam de evoluir com o passar do tempo, à medida que se constrói a instituição museal, à medida que se constrói a disciplina da história da arte, à medida que o museu evolui porque a história da arte evolui, e que cresce o sentimento de que a história da arte deve levar em conta todas as formas de criação.

\footnotetext{
"Título original: "Le collectionneur et le musée, ou comment infléchir l'histoire de l'art?" O artigo foi publicado pela primeira vez em RECHT, Roland; SÉNÉCHAL, Philippe; BARBILLON, Claire; MARTIN, Françoise-René (org.) Histoire de l'histoire de l'art en France au XIXe siècle. Paris: La documentation Française / Collège de France / INHA, 2008, p. 243-253.O livro reúne as contribuições ao Colóquio internacional realizado em Paris de 2 a 5 de junho de 2004, organizado pelo Institut d'histoire de l'art em parceria com o Collège de France. http://www.ladocumentationfrancaise.fr/catalogue/9782 I I006539 I/

* Historiadora e antropóloga de formação, atuou como curadora do Museu d'Orsay desde o início de seu projeto nos anos 1980, tendo realizado as exposições 1848, la République et l'art vivant (1998) e La Forêt de Fontainebleau, un atelier grandeur nature (2007), dentre outras. É pesquisadora do Institut national d'histoire de l'art em Paris, onde coordena pesquisa sobre a história do gosto, investigando as coleções privadas francesas do século XVIII ao início do XX; e-mail: chantal.georgel@inha.fr

**** Doutora em História da Arte pela Université de Paris I Panthéon-Sorbonne, é professora de História da Arte na Escola de Belas Artes da UFRJ onde atua no Programa de Pós-Graduação em Artes Visuais e coordena grupo de pesquisa sobre a relação entre crítica e produção artística no século XIX e início do XX no Brasil. É integrante dos grupos de pesquisa Entresséculos (EBA/UFRJ) e Modos de ver (UFRJ/ UnB/Unicamp); anacanti@ufri.br
}

I Monsieur Jourdain é um personagem de Molière, Le bourgeois gentilhomme (1670). Nota da tradutora. 
O problema, aparentemente simples, é complexo e não se pode resolvêlo em tão pouco tempo. Proponho, então, para ser objetiva e voltar ao foco da questão - a contribuição (real, involuntária, positiva ou negativa) do colecionador para a história da arte por esse meio muito particular que é o museu - partir de uma constatação que todos conhecemos. Na França, os museus nasceram e se desenvolveram frequentemente com a transferência de coleções privadas ao público: transferência (a primeira de todas) em 1694 da coleção Boisot (excoleção Perrenot de Granvelle) em Besançon, transferência das coleções reais ao Museu das Artes em 1793; transferência aqui e acolá das coleções apreendidas aos emigrantes. A história continuou ao longo dos séculos e se prolonga nos dias de hoje: pensemos nas cento e dez obras legadas por Maurice Jardot a Belfort em $1996^{2}$ e em Paul Dini ${ }^{3}$ que doou mais de quatrocentos quadros a Villefranche-sur-Saône em 1997. Para ficar no século XIX, podemos citar alguns exemplos: em 1808 a cidade de Nantes entra em possessão de 1155 quadros e 10646 gravuras dos irmãos Cacault; em 1837, a cidade de Montpellier abre um museu constituído de 328 quadros doados e legados por François-Xavier Fabre; em 1842, cabem à cidade de Ajaccio várias centenas (8I5) de quadros e objetos de arte provenientes da coleção do Cardeal Fesch"; em 1869, o Museu do Louvre recebe uma de suas mais prestigiosas doações, 582 quadros do doutor La Caze; em 1894, Jean Gigoux lega à cidade de Besançon 460 quadros e 3000 desenhos; em 1903, Fourché doa a Orleans 340 quadros e 300 desenhos... e daí por diante! Será possível imaginar que essas doações massivas de coleções aos museus não tenham modificado a direção da história da arte, sabendo precisamente que são coleções e não simples conjuntos aleatórios? Pode-se imaginar tudo, claro, mas imaginar corretamente pressupõe que se saiba bem do que se fala quando se fala dos museus e de sua suposta relação com a história da arte. "Os museus são necessários aos historiadores da arte", afirmava Henri Focillon no início do século XX; sem dúvida, pois o museu dá visibilidade às obras, permitindo assim aos historiadores da arte responder a algumas de suas interrogações de base: quem pintou tal ou tal quadro? O que ele representa? Quando foi feito? Qual é o seu estilo? Porém, um século antes não era disso que se tratava: em primeiro lugar o museu tinha como missão, além de afirmar a supremacia da nação, propagar o amor à arte, refinar o gosto, fornecer modelos aos artistas. Era por isso que o colecionador fazia questão de transmitir sua coleção a uma coletividade pública, pretendia assim cumprir uma missão de ordem social. Não se tratava de história da arte! E no entanto, a história da arte estava bem ali, escondida talvez, mas inevitavelmente presente já que toda obra exposta penetra de facto, simplesmente por estar visível, no domínio do conhecimento, do saber, da reflexão, no domínio portanto da história da arte. É por isso que uma página de história da arte, uma das primeiras, já estava escrita

2 Doação Maurice Jardot. Cabinet d'un amateur, en hommage à Daniel-Henry Kahnweiler, Paris, RMN, 1999.

3 Le Choix d'un collectionneur, une histoire de la peinture à Lyon et en Rhône-Alpes depuis 1875, cat. exp. (Villefranche-sur-Saône, musée Paul Dini, I 0 juin - 7 octobre 200I),Villefranche-sur-Saône, Centre culturel de Villefranche, 200I.

4 Havia 16000 quadros no inventário após a morte do cardeal em I839, sendo 250 Primitivos italianos; 815 quadros foram doados à cidade de Ajaccio sendo 40 Primitivos italianos. Ver Dominique Thiébaut, Ajaccio, musée Fesch. Les Primitifs italiens, Paris, RMN, 1987, p. 5-42; e Philippe Costamagna, "Données historiques de la collection Fesch" dans Le goût pour la peinture italienne autour de 1800. Prédecesseurs, modèles et concurrents du cardinal Fesch, Actes du colloque, Ajaccio, I er au 4 mars 2005, (Organização Olivier Bonfait, Philippe Costamagna e Monica Preti-Hamard) Ajaccio,Ville d'Ajaccio, 2006, p. 2 I-32. 
ou em gestação nas paredes do primeiro museu. Por um lado, era uma história da arte convencional ou conforme, feita de grandes nomes de mestres conhecidos e reconhecidos, presentes nas coleções reais logo aumentadas, durante certo tempo, com o melhor das coleções holandesas, alemães, espanholas (em pequena quantidade, quanto a essas últimas) e sobretudo italianas, não sem talento e com determinação por Dominique-Vivant Denon, ele mesmo ilustre colecionador. Incluem-se ainda nessa "primeira página de história da arte", as coleções apreendidas aos emigrantes, os Robien, Tessé e outros Jehannin de Chamblanc, formadas no século XVII e sobretudo no século XVIII, igualmente conformes, conformes em particular ao gosto dos colecionadores do tempo passado que elas contribuiriam a fixar, consagrar, cristalizar, enquanto por outro lado, já se apresentavam, felizmente, os primeiros desvios de uma história da arte escrita por colecionadores... pouco impregnados de história da arte. Devemos insistir nessa virada do século XVIII ao XIX, tão rica de ocasiões, em que o colecionismo mostraria seus primeiros efeitos sobre o museu nascente e sobre a história da arte que estava por vir. Fico tentada a vos contar tudo isso como se conta uma bela história, história estudada por outros, tais como Francis Haskell, Antoine Schnapper, Krzysztof Pomian, aos quais me agrada prestar homenagem aqui. Era uma vez um país maravilhoso, a Itália, abundante de obras de arte.

Nesse país abalado pela guerra e que se tornara francês, onde antigas fortunas desapareciam enquanto novas surgiam, se assistiria a uma espécie de êxodo massivo de obras e de coleções inteiras, para a Inglaterra, e sobretudo para a França. Enquanto os poderes públicos e seus epígonos (a grosso modo a família Bonaparte, tio e irmão) se apoderavam facilmente do melhor, do mais renomado e mais caro, um pequeno número de diplomatas e de artistas que viviam e trabalhavam na Itália, primeiramente em Roma, constituíam belas coleções, é certo. Entretanto, porque eram mais ou menos afortunados, porque - Estado controlava o conjunto das transações velando para que o melhor fosse para o museu, porque formavam um grupo de amigos (uma espécie de rede ou de colônia) todos ligados a Séroux d'Agincourt e Artaud de Montor, promotores (sem intenção no que concerne Séroux d'Agincourt ${ }^{5}$ ) de uma arte italiana cuja legitimidade já não se resumia aos esplendores da Antiguidade e do Renascimento, François-Xavier Fabre, François Cacault, Pierre-Adrien Pâris ${ }^{6}$, Jean-Baptiste Wicar, e ainda Dominique-Vivant Denon ${ }^{7}$, homem de "duas cabeças" e dupla função, compraram um pouco de tudo, mas sobretudo obras que pouco ou nada interessavam aos poderes públicos: as obras italianas mais antigas, ou ao contrário as mais recentes, obras dos contemporâneos menos cotados, desenhos dos grandes mestres. Compraram obras desconhecidas, ainda ausentes do campo de estudos e reflexão dos historiadores, e que deveriam, porque foram transmitidas a algum museu, assumir um dia seu lugar na história da arte, por vezes muito mais tarde. Pensemos por exemplo nos dois Georges de La Tour ( $O$ tocador de realejo e São José e o Anjo) da coleção Cacault, que

5 Jean-Baptiste-Louis-Georges Séroux d'Agincourt, Histoire de l'art par les monuments depuis sa décadence au IVe siècle jusqu'à son renouvellement au XVle, Paris, Treuttel et Würtz, I823.

6 Pierre-Adrien Pâris legou ao museu de Besançon, em 14 de maio de 1818, milhares de desenhos e 38 quadros, todos de seus contemporâneos (Fragonard, Hubert Robert, Marguerite Gérard...).

7 Marie-Anne Dupuy, “C'est mon sort d'avoir un cabinet”, dans Dominique-Vivant Denon, L'oeil de Napoléon, (Org. Marie-Anne Dupuy), cat. exp. (Paris, Museu do Louvre, 20 out. 1999 - 17 jan. 2000), Paris, RMN, 1999 , p. $392-400$. 
em seu tempo ele atribuíra a Murillo e a Seghers. Por um lado, mantinha-se e se consagrava uma hierarquia que privilegiava as obras do Cinquecento e do Seicento, por outro, dava-se oportunidade àqueles que seriam chamados de "Primitivos" e também aos quase contemporâneos, Fra Angelico, Giotto, Memling, mas também a Tiepolo, Watteau, Fragonard.

Esse balanço inicial do primeiro encontro entre o colecionador, o museu e a história da arte foi claramente definido porArtaud de Montor em I808:"pouco convém a um particular pensar em reunir os quadros autênticos de Rafael, de Correggio, de Giulio Romano, do Domenichino e de tantos outros grandes homens. Uma coleção desse gênero que não seja de um governo poderoso só pode ser incompleta. Mas com um pouco de zelo, cuidados infinitos, sacrifícios e paciência, conseguimos formar a coleção que apresento no catálogo, bastante completa para ajudar, algum dia, uma mão mais treinada que a minha a compor a história geral da arte dessa época no que se refere à Itália"8.

O papel do colecionador que teria por missão compor a história geral da arte (ou ajudar a compô-la) se esboçou perfeitamente na figura de DominiqueVivant Denon. Como diretor do Louvre, ele insuflou no Museu, para o qual angariou as mais notáveis obras-primas, uma pitada de vanguardismo (se posso falar assim) ao enriquecê-lo com uma pequena e brilhante coleção de Primitivos alemães e italianos que ele mesmo reunira'.

Mas vejamos o desenrolar dos acontecimentos. Enquanto a história da arte produzia seus primeiros textos, o museu se multiplicava e se transformava. Abandonando as montagens puramente funcionais ou estéticas, passava a classificar, organizar e se lançar na cronologia, ou seja, na história da qual se fazia assim o auxiliar. Théophile Gautier festejava essas mudanças: "o museu ganhou um aspecto inteiramente novo graças aos senhores Jeanron e Villot e, desde a remodelação da seção de pinturas, parece dez vezes mais rico [...]. Outrora os quadros eram pendurados aqui e acolá, mais ou menos ao acaso ou de acordo com suas dimensões e os cantos das molduras, sem preocupação com a cronologia [...]. Parecia uma loja repleta de maravilhas, e não um museu [...]. Agora uma visita ao museu é um curso de arte completo cujos professores, mesmo mudos, não deixam de ser eloquentes"'10.

Estávamos em 1849, em meados do século XIX. Teria o museu, ao adotar em seu modo de exposição os princípios de classificação herdados dos primeiros historiadores da arte, se tornado plenamente lugar de história? Será que a contribuição dos colecionadores deveria a partir de então servir, prioritariamente, para a elaboração desses "cursos mudos de história da arte"? Tais temas provocavam o debate; debate que no curso dos anos se ampliaria. Seria o museu uma escola, um lugar de entretenimento ou um lugar de fruição estética? Debatia-se a propósito daqueles que sabem ou não ver uma obra de arte ("oculos habent et non vident"), e a propósito do colecionador - deveria ser um sábio? Era necessário que o fosse?

Descobertas, redescobertas ou rejeições já agitavam o mundo dos

8 Alexis-François Artaud de Montor, Considérations sur l'état de la peinture dans les quatre siècles qui ont précédé celui de Raphaël, par un membre de l'Académie de Cortone (Artaud de Montor), ouvrage servant de catalogue raisonné à une collection de tableaux des XII', XIIle, XIVee et XVe siècles, Paris, Mongié, I808.

9 Monica Preti-Hamard, “L'Exposition des écoles 'primitives' au Louvre, la partie historique qui manquait au musée", In Dominique-Vivant Denon, L'oeil de Napoléon, op. cit. nota 7, p. 226-253.

10 Théophile Gautier. “Études sur les musées. Le musée ancien”, La Presse, 10 fev. 1849. 
historiadores. No meio disso tudo, numerosos colecionadores continuavam a colecionar e, ao que parece, colecionar sem se preocupar com a história, seguindo apenas o "gosto da época" e por vezes as recomendações de um ou outro desses manuais de conselhos que, de Dezallier d'Argenville" a André Fage $^{12}$, passando por François-Xavier de Burtin ${ }^{13}$ e Gault de Saint-Germain ${ }^{14}$, Ihes recomendavam a norma e a moderação. Foi à luz desses tratados que em 1828 a cidade de Bordeaux considerou aceitável comprar os 265 quadros da coleção do marquês de Lacaze pela soma de 80.000 francos $^{15}$, uma coleção bem dentro da norma e da qual se diria um século mais tarde que "trouxe mais abundância que verdadeira beleza".

Essas coleções de amadores que hoje estão nos museus eram numerosas e compostas em sua maioria, a exemplo da coleção Lorin (II7 quadros) fundadora do museu Bourg-en-Bresse em $1853^{16}$-, de um pouco de tudo: obras dos séculos $\mathrm{XVII}, \mathrm{XVIII} \mathrm{e} \mathrm{XIX,} \mathrm{de} \mathrm{pequeno} \mathrm{e} \mathrm{médio} \mathrm{formatos,} \mathrm{de} \mathrm{temas} \mathrm{agradáveis,}$ paisagens, cenas de gênero, naturezas-mortas, retratos, com predomínio das Escolas do Norte e da pintura francesa. São coleções reunidas ao acaso das oportunidades e dos meios, sem o propósito de compor um conjunto de referência. Podem, por outro lado, ter cada qual sua identidade, resultado da liberdade de seu autor, o que nos permite ver hoje em Cherbourg, por exemplo, graças à doação feita por Thomas Henry à cidade em I83I, a pequena pintura de gênero ou de paisagem do Império e da Restauração, "a pintura francesa moderna não oficial dos anos 1800-1830" como qualificou Jacques Foucart ${ }^{17}$. Essa mesma liberdade também nos deixa ver em Chambéry (desde I883) o maior conjunto de obras florentinas do Seicento e do Settecento existente na França, graças a Hector Garriod que as colecionou, ao mesmo tempo em que comprava para a Galleria Sabauda de Turim quadros do Cinquecento, mais raros, mais caros e mais conformes à hierarquia das artes. Podíamos e podemos vê-las, e assim estudá-las.

Na verdade, a maior parte das coleções formadas ao longo do século XIX,

11 Lettre sur le choix et l'arrangement d'un cabinet curieux écrite par M. Dézallier d'Argenville, secrétaire du roi en la Grande chancellerie, à M. de Fougeroux, trésorier-payeur des rentes à l'hôtel de ville, jun. 1727.

12 André Fage, Le Collectionneur des peintures modernes. Comment acheter, comment vendre. Tours, Imprimeries Arrault et Cie, 1930.

13 François-Xavier de Burtin, Traité théorique et pratique des connaissances qui sont nécessaires à tout amateur de tableaux, suivi d'observations sur les collections publiques et particulières, et de la description des tableaux que possède en ce moment l'auteur. Bruxelles, Weissenbruch, I808.

14 Pierre Marie Gault de Saint-Germain, Guide des amateurs de peinture dans les collections générales et particulières. Paris, Destouches, 1816 .

15 "Percebo o quanto importa aos interesses da cidade que esse objeto seja estudado com uma escrupulosa atenção, no entanto, só posso oferecer uma simples impressão, a principal causa que se opõe a que eu entre em grandes detalhes se deve à insuficiência de meus conhecimentos [...]. Baseio minhas apreciações no Traité théorique et pratique des connaissances nécessaires à tout amateur de tableaux de F.-X. de Burtin e em Le Guide des amateurs de tableaux de Gault de Saint-Germain". Relatório ao Senhor prefeito de Bordeaux, 1828. Archives municipales de Bordeaux, dossier Lacaze.

16 Antoine Lorin (1779-1847) e sua esposa legaram sua coleção à cidade de Bourg-en-Bresse em I853, o que permitiu a abertura do museu de Bourg-en-Bresse.Ver Michèle Duflot, "Antoine et François Lorin: histoire d'une collection", In 1853, un musée est né, Hommage à Antoine et François Lorin, premiers donateurs du musée de Brou (Org. Michèle Duflot e Marie-Anne Sarda), cat. exp. (Bourg-en Bresse, musée de Brou, 21 jun. 9 nov. 2003), Bourg-en-Bresse, musée de Brou, 2003, p. 55-73.

17 Jacques Foucart, "Les peintures françaises du XIXe siècle, une moderne richesse de la donation Thomas Henry”, In Le Musée Thomas Henry à Cherbourg, les collections et leur histoire, número especial da revista Art de Basse-Normandie, n. I 28, 2003, p. 43-48. 
por vezes de grande qualidade (ou não), refletiam, sem que o colecionador tivesse sempre plena consciência,uma atitude ditada precisamente pelo desenvolvimento dos estudos históricos que, em meados do século XIX, sugeriam (firmemente) a tolerância com toda forma de arte. "Não temos o direito de condenar um estilo por não se harmonizar com nossas ideias, nem de declará-lo sem valor porque somos mentalmente e constitucionalmente incapazes de apreciar sua qualidade", afirmava em I 856 o Art Journal, três anos antes da Gazette des BeauxArts fazer desse "gosto por toda a arte do passado" o seu credo, no editorial de seu primeiro número. Ao mesmo tempo em que se afirmava ser essencial manter uma hierarquia, se enfatizava a necessidade de procurar a beleza na obra de cada artista, "de Rafael até um gravador secundário como Gravelot". Esse princípio parece ter guiado a formação de numerosas coleções destinadas desde sua origem a formar um museu. Seus autores o dizem, ou deixam que outros o digam. Graças a Vivenel, que em 1843 ofereceu a sua cidade natal uma "enciclopédia resumida de todas as artes em todos os países e entre todos os povos", não há "uma criação do gênero humano que não esteja gloriosamente representada no museu de Compiègne"|8! Encontra-se o mesmo entusiasmo em Quimper, orgulhosa em I 864 do legado do barão de Silguy que doou suas I200 pinturas, 200 desenhos e 12000 gravuras, de todas as escolas, da Idade Média a 1842! Por toda parte se sonhava com enciclopédias, com retrospectivas e resumos históricos, trate-se de pintura ou escultura. Em maio de 1882, Auguste Giffard oferece à cidade de Angers "algo inteiramente excepcional do ponto de vista particular da escultura: uma coleção representando a história dessa arte"|9. A mesma intenção se encontrava entre os melhores connaisseurs: Bonnat, pintor sem gênio mas colecionador inspirado, em especial de desenhos, confessava formar sua coleção "sem ostracismo, com o mesmo amor por todos os meios de expressão, todas as formas, todos os ideais" ${ }^{20}$. Tal sonho assombrava tanto as províncias quanto Paris. No Louvre, o sonho se realiza em I878, quando His de la Salle oferece "um resumo completo e requintado daquilo que o desenho produziu de mais belo e de mais puro desde o século XIV até os nossos dias"21. No entanto esmorece alguns anos mais tarde, quando o museu é obrigado a aceitar a coleção de Thiers, reunião de "peças justificativas de um quadro histórico da arte", nem todas de primeira ordem ${ }^{22}$ !

Tal qual a serpente que morde a própria cauda, os colecionadores contribuíam a fixar no museu uma visão histórica, universalista, enciclopédica, a mesma visão que fundamentara a formação de suas coleções, por vezes em

18 "Uma enciclopédia resumida de todas as artes, em todos os tempos e entre todos os povos, escultura, pintura, cerâmica, vidro, mobiliário, armas, serralharia, joias, ourivesaria, relojoaria, esmaltes, curiosidades egípcias, hindus, chinesas, japonesas, medalhas, glíptica, não há uma criação do gênio humano que não esteja gloriosamente representada no museu de Compiègne", carta de Eugène Pelletan a Félicien Mallefille, julho de I870, citada por Sylvie Forestier, “La Création du musée Vivenel (I84I)”, Bulletin de la Société historique de Compiègne, 1979, p. 130.

19 "Amando as artes e minha cidade como o disse, tinha [ilisível] no interesse de todos, de fundar no museu Saint-Jean, que está perfeitamente apto em todos os aspectos, algo inteiramente excepcional do ponto de vista particular da escultura: uma coleção representando a história dessa arte", carta de Auguste Giffard endereçada ao prefeito de Angers em 22 de maio de 1882. Archives municipales de Angers, AM.2.R40.

20 Léon Bonnat, “Comment je suis devenu collectionneur”, La Revue de Paris, 20 jun, I893, p. 757-764.

21 His de la Salle (1795-1878) legou (testamento de 28 de abril de 1878) sua coleção de 620 desenhos. Ver Charles Ephrussi, “Les dessins de la collection His de la Salle”, Gazette des Beaux-Arts, XXV, $2^{\mathrm{e}}$ per., mar. I882, p. 224-245.

22 Charles Blanc, Collection d'objets d'art de M.Thiers léguée au Louvre. Paris, I884. 
detrimento do Belo. Pensemos no "Museu das reproduções das obras-primas da arte" oferecido ao Estado em 1911 pelo professor Lannelongue com o objetivo de criar "um museu de ensino da arte universal"23.

O decreto da série, - do "completo" e da "sequência" (para usar a linguagem da época), sem os quais "cada pedaço se vê deslocado, sem filiação, como um órfão" -, que antecede todo estudo histórico de qualquer forma de arte, impõe ao museu a tarefa de "preencher suas lacunas" (é um leitmotiv), o que se faz graças aos colecionadores aos quais se atribui agora o papel de "completar" as séries existentes, ou fundar novas. Eles são convocados, muitas vezes pela imprensa, a completar tal ou tal série "de um interesse tão grande para a história de nossas artes". A isso se dedicam aliás, no final do século XIX, esses grandes colecionadores e doadores que são Davillier, os irmãos Dutuit, Ernest Grandidier, Eugène Piot ou ainda Jules Maciet, cujos famosos álbuns são emblemáticos dessa vontade de relocar as obras não apenas no curso de sua história, mas também no curso da história da arte mundial, vontade que justifica as doações ou legados, cá e lá, de numerosos conjuntos de estampas. Em 1898 , por exemplo, Charles Thévenot doou à cidade de Dijon, para seu museu, 324I 5 gravuras, 1700 fotografias e 21215 recortes de jornais.

Os colecionadores adotam o enfoque do historiador que viaja, compara, estuda, emite hipóteses, escreve ${ }^{24}$. Observa-se que aumenta a necessidade dos próprios colecionadores apresentarem por escrito suas escolhas estéticas em termos de cultura e de pseudocultura. Os comentários eruditos sobre as obras e os artistas que integram suas coleções se multiplicam. Já não há coleção sem catálogo escrito pelo próprio colecionador, por mais modesto que seja, como foi o caso do doutor Escallier, o qual, sem jamais ter recebido formação artística, sem ter condições de viajar (só podia ir a Paris, ao Louvre), reuniu uma coleção de 176 quadros - essencialmente flamengos e holandeses dos séculos XV e XVI, dentre os quais a obra-prima é o Políptico de Anchin, doados a Douai em I857 -, acompanhados de um catálogo, no qual cada obra recebeu sua atribuição (tirada do Dictionnaire des monogrammes, marques figurées, initiales, noms abrégés, etc. de François Brulliot, publicado em 1832) e uma notícia histórica redigida graças aos livros presentes na biblioteca municipal de Douai ${ }^{25}$. Mais afortunado, mais ambicioso também, o barão Davillier ${ }^{26}$ redige sua Histoire des faïences hispanomauresques à reflets métalliques, à medida que constrói sua coleção que lega ao Louvre em 1883, "peças que não são talvez todas de primeira categoria",

230 museu Lannelongue, inaugurado em II de dezembro de 19 II em Castera-Verduzan (Gers), pretendia mostrar "a arte escultural de nossas catedrais, o encanto dos afrescos italianos, a grandeza de um Claus Sluter, a emoção profunda de um Rembrandt, a nobreza de um Poussin, todos os sentimentos da forma, todos os modos de expressão do sentimento da natureza, até as composições eurítmicas de um Puvis de Chavannes, a ousadia do desenho de um Degas, a magia da luz de um Turner ou de um Claude Monet", Musée Lannelongue à Castera-Verduzan. Catalogue des photographies, gravures et moulages par Carle Dreyfus. Paris, 1911 . O texto é de Claude Migeon.

24 "Para ser um amador cultivado, é necessário visitar todos os museus, assim como as coleções particulares, anotar o que falta, comprar em seguida os pedaços que forem sendo encontrados", carta de Eugène Dutuit a seu irmão, em 6 de julho de 1878, citada por Mathilde Avisseau, "La collection d'antiquités de deux bourgeois amateurs du XIXe siècle, les frères Dutuit", In L'Anticomanie. La collection d'antiquités aux XVIII e et XIX' siècles (Org. Annie-France Laurens e Krzysztof Pomian). Paris, EHESS, I 992, p. 299.

25 Benoît Delcourte, “Une Collection de tableaux au musée de Douai: le legs Escallier”, monografia da École du Louvre, Mss, 2003-2004.

26 J.-C. [Jean-Charles, baron] Davillier, Histoire des faïences hispano-mauresques à reflets métalliques. Paris, Victor Didron, I86I. 
confessa Molinier ${ }^{27}$, conservador do departamento dos Objetos de arte, "mas todas tem sua importância do ponto de vista histórico". Ernest Grandidier forma uma coleção de cerâmica chinesa e publica um livro sobre a dita coleção em $1894^{28}$, antes de doá-la ao Louvre. "A partir das peças de sua coleção, redigiu uma história da porcelana” dirá Koechlin prestando-lhe homenagem em 191429. Esses colecionadores fizeram entrar no museu milhares de obras e objetos, seções inteiras da história da criação artística, acrescentando assim, segundo o desejo expresso por Piot desde 1842 (aos trinta anos de idade) "uma pedra a esse vasto monumento que durante muito tempo permanecerá inacabado: a história da arte" 30 .

A união da História, do colecionador e do museu chega ao apogeu, ao que parece, nas últimas décadas do século XIX.A atividade está no auge e há mesmo uma moda, não apenas de colecionar, mas de colecionar para doar a um museu, uma moda que chega aos extremos da caricatura. $O$ colecionador Albert Robida reúne, por exemplo, toda sorte de coleções, entre as quais uma coleção de bassinoires ${ }^{31}$, com as quais encheu duas salas de seu apartamento e sobre as quais se propôs escrever um livro - Les Bassinoires de la Renaissance au XVIIlle siècle, recherches historiques, artistiques et archéologiques -, antes de oferecê-las a Compiègne, sua cidade natal ${ }^{32}$ ! Estamos em I885, momento em que, devese ressaltar pois certamente não é por acaso, se institucionaliza o ensino da história da arte na França ${ }^{33}$. Em especial, acabara de ser criada a École du Louvre, com o objetivo de "tirar das coleções o conhecimento que elas contém" 34 , sentença à qual responde Ernest Grandidier em 1890, como um eco, ao lembrar que "frequentemente nos esquecemos que uma coleção não é apenas uma distração, mas antes de mais nada um ensinamento prático" 35 .

Em I803, Séroux d'Agincourt escrevia: "aquilo que dei a conhecer [da história da arte] poderia ser comparado a um imenso museu". Um século mais tarde - na virada do XIX para o XX - não era possível comparar o museu a um imenso curso de história da arte? A história - e sabe-se o quanto alguns lamentaram - tinha se apoderado do museu! Uma inversão de valores estava em andamento: logo não seria o museu que estaria a serviço da arte, mas a arte a serviço do museu, da história e do passado; ao menos era isso que se

27 Émile Molinier, Rapport au directeur des musées nationaux, 4 février 1884. Paris, Archives des musées nationaux (AM8).

28 Ernest Grandidier, La céramique chinoise, porcelaine orientale: date de sa découverte, explication des sujets de décor, les usages divers, classification. Paris, Firmin-Didot, 1894.

29 Raymond Koechlin, Les Collections d'Extrême-Orient au musée du Louvre et la donation Grandidier. Paris, Imprimérie générale Lahure, 1914.

30 Louis Courajod, “Eugène Piot et les objets d'art légués au musée du Louvre”, Gazette des Beaux-Arts, mai 1890 , p. 397-4I2.

31 Recipiente de cobre perfurado que, cheio de brasas, servia outrora para esquentar camas. Nota da tradutora.

32 Le Dix-neuvième siècle, textes e dessins par Albert Robida, Paris, 1888.

33 A primeira cátedra de história da arte (arte e arqueologia) foi criada na Sorbonne em 1876; em I878 é criada a cátedra de história da arte e estética no Collège de France (por Charles Blanc); em I 882 é criada a École du Louvre; novas cátedras de história da arte aparecem em seguida em Lille (1890), Paris (1896), Lyon (1898).

34 Artigo I do Regulamento da École du Louvre, 27 de julho de 1882.

35 Sem referência bibliográfica. No original em francês: "qu'on oublie trop souvent qu'une collection n'est pas uniquement une distraction mais avant tout un enseignement pratique". Nota da tradutora. 
pretendia, e com a ajuda eficaz dos colecionadores. Devemos sublinhar que os anos 1890-1914 constituem uma idade de ouro em matéria de doações e legados aos museus. Véronique Long, que estudou o exemplo do Louvre, observa que 236 coleções (de uma a cinquenta obras, ou mais) entraram no museu entre 1873 e 1914, das quais dois terços entre 1891 e $1914^{36}$. Essas coleções retrospectivas são abertas a todas as formas de arte, como se tudo agora dependesse do museu e do estudo, mas fundadas prioritariamente sobre valores estabelecidos e reconhecidos. Pesquisando as doações e legados dos colecionadores aos museus de província, observo exatamente o mesmo fenômeno, seguindo a mesma cronologia: por toda parte, os colecionadores se esforçam para transmitir sua coleção, modesta ou de prestígio, a Châlonssur-Marne, Morlaix,Aix-les-Bains, Béziers, Nantes, Fougères, Bayeux, Carpentras, Gray, Nice, Saintes, Orleans... Por toda parte se multiplicam as coleções, a ponto de alguns perceberem esse fenômeno como um ataque! "A segunda metade desse século entrará para a história do gosto dos franceses como um período de nobre curiosidade", dizia Chennevières em $1890^{37}$; certo, mas o que fazer diante do museu que se constrói assim como o lugar por excelência de exposição de uma história da qual alguns reconhecem perfeitamente os limites e as recusas?

O que fazer senão desesperar-se como esse homem que assistiu aterrado à inauguração da coleção Dutuit no Petit Palais em 1902 - "Quanta história para bibelôs e mais bibelôs!" - e que, incapaz de fazer ouvir a voz da novidade, só pode reagir com desprezo. "Não me falem dos colecionadores", lançou aos jornalistas, antes de lhes dar as $\operatorname{costas}^{38}$. O que fazer, senão procurar por todos os meios, e entre esses o poderoso instrumento da coleção, mudar o curso dessa história? Não por acaso assistimos, a partir de 1870, à margem do impulso contínuo do colecionismo convencional, a atos cada vez menos isolados, atos preciosos e desafiadores. São desafios de colecionadores empenhados em afirmar sua liberdade diante do conformismo, comprometidos em escrever uma nova história da arte, preocupados ao verem os interesses da arte sendo sacrificados em prol da história.

Bruyas foi um pioneiro. Em 1876, ao legar a Montpellier sua magnífica coleção, pretendia desenhar um novo quadro histórico e escrever uma "história da arte moderna" que começava com David (deixou inacabada uma obra que seria intitulada L'Art moderne en France, odyssée de la peinture ou sérieuses recherches de la vérité). Tal projeto Ihe valeu o epitáfio imaginário de Van Gogh: "Bruyas de Montpellier é uma pessoa importante para a história da arte" ${ }^{39}$. No mesmo ano, Gustave Caillebotte redigia seu testamento. Tinha vinte e oito anos de idade e nada era urgente; e no entanto legava ao Estado um conjunto de obras de Renoir, Manet, Monet, Pissarro, Degas, Cézanne, Sisley... que já eram chamados de impressionistas. Sabia que o público não os aceitaria, mas pedia ao Estado que os conservasse até que 0 público admitisse essa pintura ${ }^{40}$. Lançava assim um desafio ao tempo, à sociedade, à história da arte. Desafio nem tão

36 Véronique Long. “Les collectionneurs d'oeuvres d'art et la donation au musée à la fin du XIXe siècle: I'exemple du Louvre", Romantisme, n. II2, 200 I, p. 45-54.

37 Henry de Chennevières, Silhouettes de collectionneurs: Eudoxe Marcille, Paris, s. n., 1980.

38 L'Illustration, 13 dez. 1902.

39 Philippe Bordes, “Montpellier, Bruyas et Courbet”, in Courbet à Montpellier, cat. exp. (Montpellier, musée Fabre, 5 nov - 29 dez 1985), Montpellier,Ville de Montpellier, p. 23-38.

40 O testamento de Gustave Caillebotte data de 3 de novembro de 1876. 
bem sucedido, como se sabe ${ }^{4 l}$. Desafio inteiramente frustrado, por outro lado, para François Depeaux que em 1903 teve a oferta de sua coleção de telas impressionistas, entre as quais figuravam as Catedrais de Monet, recusada pela cidade e pelo museu de Rouen ${ }^{42}$. Mais felizes foram Isaac de Camondo ${ }^{43}$ e Étienne Moreau-Nélanton. Conseguiram introduzir a arte moderna no Louvre antes de 1914 e fizeram entrar no museu, ainda vivos, Degas e Monet ${ }^{44}$. Assim, essa arte tão ridicularizada em sua origem assumia um lugar no curso da história da arte, uma história escrita pelos colecionadores mas consagrada pela autoridade do museu. Uma arte ontem, um patrimônio hoje. E amanhã?

O amanhã parece ser justamente a primeira preocupação do colecionadordoador (que representa menos de 10\% do total de colecionadores), para além das palavras, das declarações, para além de uma história da arte que se pretendia ou gostaria de escrever e modificar. Amanhã e a eternidade, uma eternidade contrária à história, mas que o museu promete, pois se é verdade que ele presta serviço à história, também está a serviço da arte.

Tradução recebida em abril de 20/4. Aprovado em junho de 20/4

41 Pierre Vaisse esclareceu o caso do legado Caillebotte. Conferir em PierreVaisse, "L'impressionnisme au musée: le legs Caillebotte", L'Histoire, n. I58, set 1992, p. 7-I4.

42 François Bergot, “La donation François Depeaux au musée des Beaux-Arts de Rouen”. In Hommage à Hubert Landais, Arts, Objets d'art, Collections. Études sur l'art du Moyen Âge e de la Renaissance, sur l'histoire du goût et des collections. Paris: Blanchard, 1987, p. 205-2II.

43 Isaac de Camondo, em testamento de 18 de dezembro de 1908, aceito em 8 de maio de 1911, legava ao Louvre uma importante coleção de objetos de arte e uma coleção de telas "modernas" entre as quais Lola de Valence e Le Fifre de Manet, Les Repasseuses de Degas...

44 Chantal Georgel, "Il est un temps pour conserver et un temps pour rejeter". In Passions privées. Collections d'art moderne et contemporain en France, cat. exp. (Paris, Musée d'art moderne de la Ville de Paris, dez. 1995 - mar. 1996). Paris, Paris-Musées, 1995, p. 39-45. 